\title{
Dibenzothiophene/Oxide and Quinoxaline/Pyrazine Derivatives Serving as Electron-Transport Materials**
}

\author{
By Tai-Hsiang Huang, Wha-Tzong Whang, ${ }^{*}$ Jiun Yi Shen, Yuh-Sheng Wen, Jiann T. Lin,* Tung-Huei Ke, \\ Li-Yin Chen, and Chung-Chih Wu*
}

A series of 2,8-disubstituted dibenzothiophene and 2,8-disubstituted dibenzothiophene-S,S-dioxide derivatives containing quinoxaline and pyrazine moieties are synthesized via three key steps: i) palladium-catalyzed Sonogashira coupling reaction to form dialkynes; ii) conversion of the dialkynes to diones; and iii) condensation of the diones with diamines. Single-crystal characterization of 2,8-di(6,7-dimethyl-3-phenyl-2-quinoxalinyl)-5H-5 $\lambda^{6}$-dibenzo[b,d]thiophene-5,5-dione indicates a triclinic crystal structure with space group $P 1$ and a non-coplanar structure. These new materials are amorphous, with glass-transition temperatures ranging from 132 to $194{ }^{\circ} \mathrm{C}$. The compounds (Cpd) exhibit high electron mobilities and serve as effective electron-transport materials for organic light-emitting devices. Double-layer devices are fabricated with the structure indium tin oxide (ITO)/Qn/Cpd/LiF/Al, where yellow-emitting 2,3-bis[4-( $N$-phenyl-9-ethyl-3-carbazolylamino)phenyl]quinoxaline $(\mathrm{Qn})$ serves as the emitting layer. An external quantum efficiency of $1.41 \%$, a power efficiency of $4.94 \mathrm{~lm} \mathrm{~W}^{-1}$, and a current efficiency of $1.62 \mathrm{~cd} \mathrm{~A}^{-1}$ are achieved at a current density of $100 \mathrm{~mA} \mathrm{~cm}^{-2}$.

\section{Introduction}

Organic and polymer light-emitting diodes (OLEDs and PLEDs) based on small molecules and conjugated polymers are considered to be promising candidates for the next generation of flat-panel displays. ${ }^{[1]}$ After Tang and Van Slyke's ${ }^{[2]}$ discovery in 1987, and that of Burroughes et al.$^{[3]}$ in 1990, rapid progress has been made on device performances. To date, many small molecules containing electron-rich aromatic amines have been widely used as hole-transport and/or emitting materials in electroluminescent devices, exhibiting good

[*] Dr. W.-T. Whang, T.-H. Huang

Department of Materials Science and Engineering

National Chiao Tung University

1001 Ta Hsueh Rd, Hsin Chu 300 (Taiwan)

E-mail:wtwhang@cc.nctu

Dr. J. T. Lin, J. Y. Shen, Y.-S. Wen

Institute of Chemistry, Academia Sinica

Taipei 115 (Taiwan)

E-mail: jtlin@chem.sinica.edu.tw

Dr. J. T. Lin, J. Y. Shen, Y.-S. Wen

Department of Chemistry

National Central University

Chungli 320 (Taiwan)

Dr. C.-C. Wu, T.-H. Ke, L.-Y. Chen

Department of Electrical Engineering

Graduate Institute of Electro-optical Engineering and Graduate Institute of Electronics Engineering

National Taiwan University, Taipei 106 (Taiwan)

E-mail: chungwu@cc.ee.ntu.edu.tw

[**] We thank the Academia Sinica, National Taiwan University, National Chiao Tung University and the National Science Council for supporting this work. Supporting Information is available from Wiley InterScience or from the authors. efficiency, brightness, and durability. ${ }^{[4]}$ In contrast, reports of the use of small molecules as electron-transporting materials are still rare in the literature. ${ }^{[5]}$ Tris-(8-hydroxyquinoline) aluminum $\left(\mathrm{Alq}_{3}\right)$ is the most widely used electron-transport material, yet its electron mobility is very low $\left(\mathrm{ca} .10^{-6} \mathrm{~cm}^{2} \mathrm{~V}^{-1} \mathrm{~s}^{-1}\right) \cdot{ }^{[6]}$ 2-(4-Biphenylyl)-5-(4-tert-butylphenyl)-1,3,4-oxadiazole (PBD) is also a widely used electron-injection/transport or hole-blocking material..$^{[7]}$ The high electron affinity $(E A=2.16 \mathrm{eV})^{[8]}$ of the oxidazole ring in the molecule is believed to play an important role in this aspect. However, PBD thin films (glass-transition temperature, $T_{\mathrm{g}}=60^{\circ} \mathrm{C}$ ) formed by vacuum deposition tend to crystallize over time, which is detrimental to device stability. ${ }^{[9]}$ Thermally stable quinoxaline compounds are another useful n-type material with high electron affinity. The quinoxaline moiety has been introduced into small molecules and polymers, and successfully applied in OLEDs and PLEDs. ${ }^{[10]}$

In this paper, we report the synthesis and characterization of thermally stable dibenzothiophene and dibenzothiophene$S, S$-dioxide-based derivatives incorporating peripheral quinoxaline/pyrazine moieties. The physical properties of these materials, carrier mobilities, and OLEDs fabricated using these compounds are investigated.

\section{Results and Discussion}

\subsection{Synthesis of the Materials}

Scheme 1 illustrates the synthesis of the dibenzothiophene or dibenzothiophene-S,S-dioxide incorporating quinoxaline and pyrazine segments. The synthetic procedures consist of three key steps: i) synthesis of 2,8-diethynyl derivatives ( $\mathbf{1}$ and 2) via a Sonogashira coupling reaction ${ }^{[11]}$ catalyzed by 


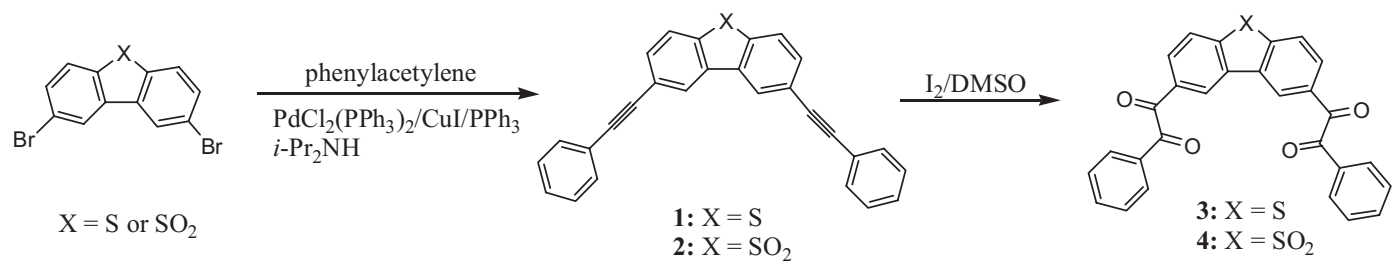

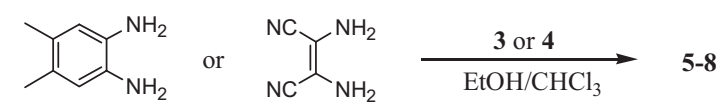

Scheme 1. Synthesis of compounds 1-8. DMSO: dimethyl sofoxide.

$\mathrm{PdCl}_{2}\left(\mathrm{PPh}_{3}\right)_{2}$ and $\mathrm{CuI}$; ii) oxidiation of the internal alkynes using iodine in dimethyl sulfoxide ( $\mathbf{3}$ and $\mathbf{4}$ ) to form the dione derivatives, in a process developed by Yusybov and Filimonov; ${ }^{[12]}$ (it is worth nothing that this method is more convenient than the similar oxidation of an alkyne to dione via the use of highly toxic selenium dioxide ${ }^{[13]}$ ) iii) condensation of a bisdione compound with an appropriate diamine to afford the targeted diquinoxaline or dipyrazine (5-8, Scheme 2$)$.

\subsection{X-Ray Crystal Structure}

The ORTEP representation of $7 \cdot \mathrm{CH}_{2} \mathrm{Cl}_{2}, \mathrm{C}_{44} \mathrm{H}_{32} \mathrm{~N}_{4} \mathrm{O}_{2} \mathrm{~S}$. $\mathrm{CH}_{2} \mathrm{Cl}_{2}$ is shown in Figure $1\left(\mathrm{CH}_{2} \mathrm{Cl}_{2}\right.$ molecules have been omitted for clarity). There are no hydrogen bonds between the $\mathrm{CH}_{2} \mathrm{Cl}_{2}$ solvent and $\mathbf{7}$, but there are very weak van der Waals' intermolecular interactions. Crystallographic data are listed in Table S1 (see Supporting Information), and important bond angles, bond distances, and parameters are collected in Tables S2-S4 (see Supporting Information). There is significant deviation of the two neighboring aromatic segments from planarity. The dihedral angles are $46.57(8)^{\circ}, 27.48(9)^{\circ}$, and $54.21(8)^{\circ}$, respectively, for the terminal phenyl plane (P2)/azine plane (P3), P3/dibenzothiophene-S,S-dioxide plane (P1), and $\mathrm{P} 1 / \mathrm{P} 2$ pairs. The twist of these aromatic rings from coplanarity

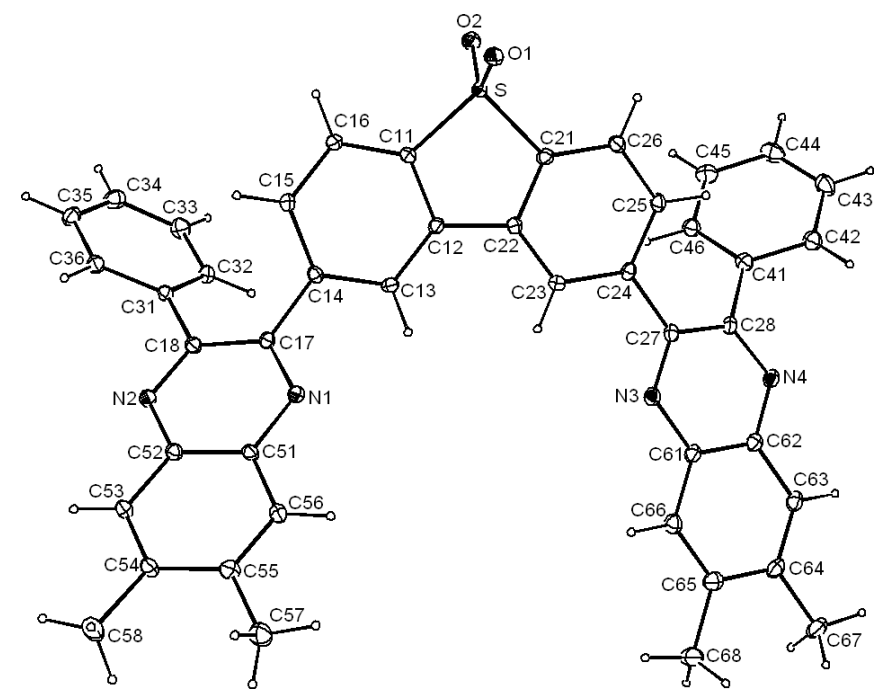

Figure 1. ORTEP drawing of 7.

tends to disfavor intermolecular stacking. The intermolecular spacing $(4.3 \AA)$ is greater than that observed for a typical $\pi-\pi$ interaction distance $\left(3.8 \AA\right.$ ).$^{[14]}$ The crystal structure of 7 (see below) indicates the lack of planarity of the molecule, and therefore there are no efficient intermolecular $\pi-\pi$ interactions, although it should be noted that the structure of a crystal grown from a solvent may not exactly reflect the real molecular packing of the deposited film.

\subsection{Photophysical Properties}

The optical absorption and photoluminescence (PL) spectra of compounds 5-8 in dilute dichloromethane solution are shown in Figures 2 and 3. All of the compounds displayed two absorption peaks: around $257-281 \mathrm{~nm}$ and $335-373 \mathrm{~nm}$. The higher-energy bands are assigned to the absorption of dibenzothiophene, dibenzothiophene- $S, S$-dioxide, and the terminal 


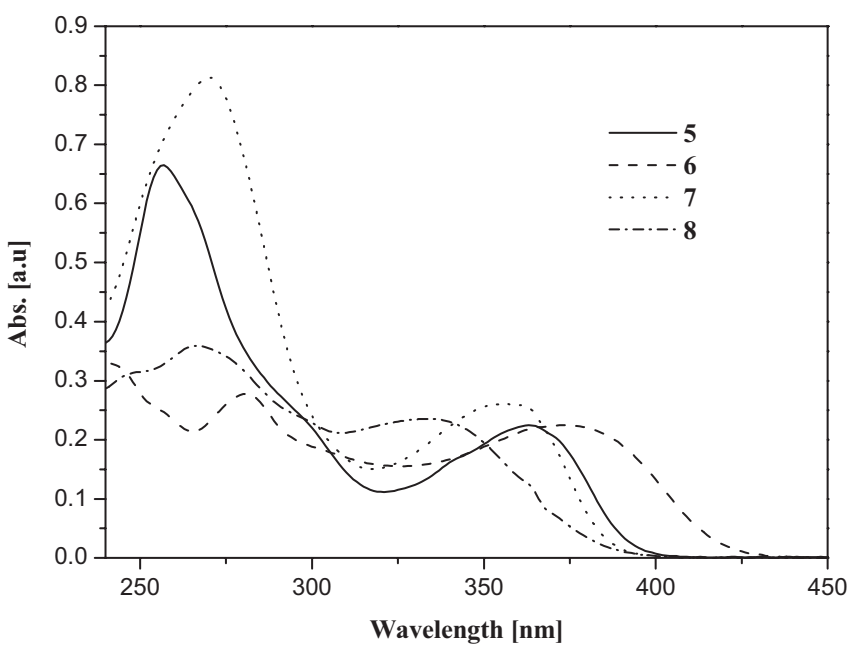

Figure 2. Electronic absorption spectra of $5-8\left(5.0 \times 10^{-5} \mathrm{~mol} \mathrm{~L}^{-1}\right.$ in dichloromethane).

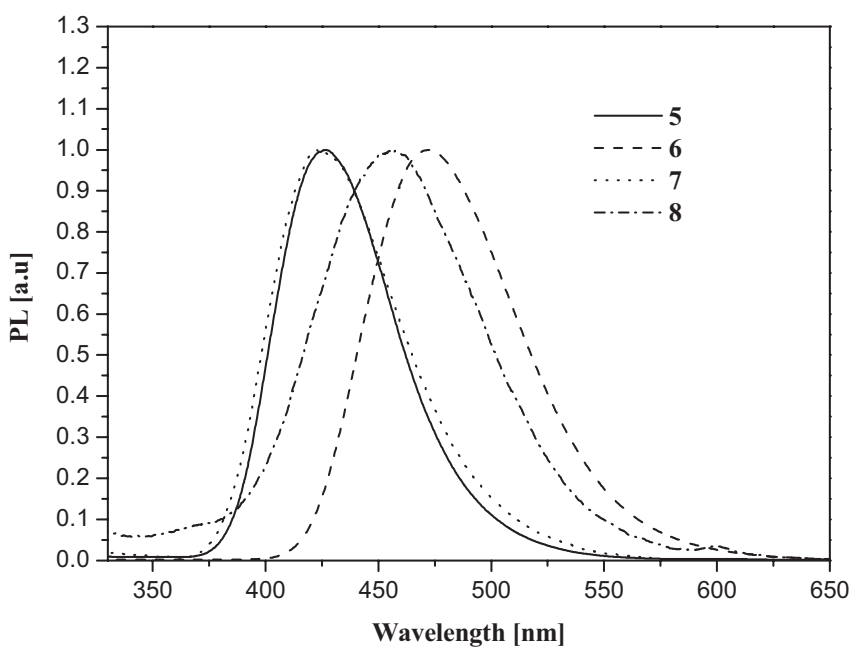

Figure 3. The emission spectra of $5-8\left(5.0 \times 10^{-6} \mathrm{~mol} \mathrm{~L}^{-1}\right.$ in dichloromethane). The excitation wavelength was $350 \mathrm{~nm}$. phenyl ring. The low-energy absorption bands are attributed to the $\pi-\pi^{*}$ transition of the quinoxaline ${ }^{[13]}$ or pyrazine ${ }^{[15]}$ moieties. These compounds are fluorescent, and the emission colors range from purplish-blue to blue-green, both in solution and the solid state. The maximum wavelength of the fluorescence of the film is only slightly red-shifted compared to that of the solution $(\Delta \lambda \mathrm{ca}$. 3-6 $\mathrm{nm}$ ). This outcome can be attributed to the non-coplanarity of the molecules (see below), which prevents "disklike" intermolecular stacking. Though it is known that quinoxaline derivatives may form an excimer upon excitation, ${ }^{[10 b, 13,16]}$ there is no evidence of excimer formation in our compounds, even at concentrations of up to $1.2 \times 10^{-3} \mathrm{M}$, or in the films.

\subsection{Thermal Properties}

The thermal properties of these materials were investigated by differential scanning calorimetry (DSC), and their thermal stability was examined by thermogravimetric analysis (TGA). The detailed data are collected in Table 1 . The experiments show that the quinoxaline/pyrazine compounds are able to form a stable glass. All the compounds exhibited isotherms with melting points $\left(T_{\mathrm{m}}\right)$ ranging from 309 to $348{ }^{\circ} \mathrm{C}$ during the first DSC heating, and readily formed a glass upon cooling $\left(30^{\circ} \mathrm{C} \mathrm{min}^{-1}\right)$. In further heating cycles, the glass transition was readily detected, and $T_{\mathrm{g}}$ ranged from 132 to $194^{\circ} \mathrm{C}$. These compounds exhibited high thermal decomposition temperatures $\left(T_{\mathrm{d}}>380^{\circ} \mathrm{C}\right)$. The $T_{\mathrm{g}}$ and $T_{\mathrm{m}}$ values for $\mathbf{6}$ and $\mathbf{8}$ are higher than those of 5 and $7\left(\Delta T_{\mathrm{g}}>20^{\circ} \mathrm{C} ; \Delta T_{\mathrm{m}}>30^{\circ} \mathrm{C}\right)$. This may be due to the introduction of the strongly polar cyano group on the pyrazine rings of $\mathbf{6}$ and $\mathbf{8}$. Similarly, the presence of the polar $\mathrm{SO}_{2}$ functional group caused a significant rise the $T_{\mathrm{g}}$ and $T_{\mathrm{m}}$ values $\left(\delta T_{\mathrm{g}}>32^{\circ} \mathrm{C}\right.$ and $\Delta T_{\mathrm{m}}>5^{\circ} \mathrm{C}$ ) in $\mathbf{7}$ and $\mathbf{8}$ compared to their dibenzothiophene congeners, $\mathbf{5}$ and $\mathbf{6}$. It is worth noting that the polar azine (quinoxaline/pyrazine) moiety is more beneficial for raising the $T_{\mathrm{g}}$ values than the diarylamino moiety: when the two azine-containing segments at the 2,8-positions of 5 and $\mathbf{6}$

Table 1. Physical data of the compounds.

\begin{tabular}{|c|c|c|c|c|c|}
\hline \multirow{2}{*}{\multicolumn{2}{|c|}{ parameter }} & \multicolumn{4}{|c|}{ Compound } \\
\hline & & 5 & 6 & 7 & 8 \\
\hline \multirow[t]{2}{*}{$\lambda_{\text {abs }}[\mathrm{nm}]$} & toluene & 364 & 370 & 355 & 335 \\
\hline & $\mathrm{CH}_{2} \mathrm{Cl}_{2}$ & 257,363 & 281,373 & 270,355 & 267,335 \\
\hline \multirow[t]{3}{*}{$\lambda_{\mathrm{em}}[\mathrm{nm}]$} & toluene & 419 & 449 & 420 & 441 \\
\hline & $\mathrm{CH}_{2} \mathrm{Cl}_{2}$ & 426 & 472 & 424 & 457 \\
\hline & film & 429 & 475 & 430 & 462 \\
\hline \multicolumn{2}{|c|}{$T_{\mathrm{m}} / T_{\mathrm{c}} / T_{\mathrm{g}} / T_{\mathrm{d}}[\mathrm{a}]\left[{ }^{\circ} \mathrm{C}\right]$} & $309 / \mathrm{NA} / 132 / 383$ & $344 / N A / 157 / 423$ & $313 / N A / 174 / 397$ & $348 / N A / 194 / 407$ \\
\hline \multicolumn{2}{|c|}{$E\left(E_{\mathrm{p}}\right)[\mathrm{b}][\mathrm{mV}]$} & $-2134(140)$ & $-1479(125)$ & $-1657(87),-2062(90)$ & $-1330(154),-1914(146)$ \\
\hline \multicolumn{2}{|c|}{$\mathrm{HOMO}[\mathrm{c}][\mathrm{eV}]$} & 5.64 & 6.19 & 6.04 & 6.59 \\
\hline \multicolumn{2}{|c|}{ LUMO [c] [eV] } & 2.58 & 3.32 & 2.92 & 3.47 \\
\hline \multicolumn{2}{|c|}{ Bandgap [c] [eV] } & 3.06 & 2.87 & 3.12 & 3.12 \\
\hline
\end{tabular}

[a] $T_{\mathrm{c}}$ : crystallization temperature; $T_{\mathrm{d}}$ : thermal decomposition temperature. [b] Measured in dimethylformamide (DMF). All potentials are reported relative to ferrocene, which was used as the internal standard in each experiment. The ferrocene oxidation potential was located at $+100 \mathrm{mV}$ relative to the $\mathrm{Ag} /$ $\mathrm{AgNO}_{3}$ non-aqueous reference electrode. The concentration of the compound was $1 \times 10^{-3} \mathrm{M}$. [c] The lowest unoccupied molecular (LUMO) energy was calculated with reference to ferrocene $(4.8 \mathrm{eV})$. A solvent-to-vacuum correction was not applied. The bandgap was derived from the observed optical edge, and the highest occupied molecular orbital (HOMO) energy was derived from the relation, bandgap=HOMO-LUMO. 
are replaced by diarylamino substituents, $T_{\mathrm{g}}$ and $T_{\mathrm{m}}$ drop by ca. 30 and $50{ }^{\circ} \mathrm{C}$, respectively. ${ }^{[\mathrm{cc}]}$

\subsection{Electrochemical Properties}

Electrochemical characteristics of the dibenzothiophene derivatives were studied by cyclic and differential pulse voltammetry. The redox potentials of these materials are listed in Table 1. The potentials are reported relative to the internal standard, ferrocene. The ferrocene oxidation potential was located at $+100 \mathrm{mV}$ relative to a $\mathrm{Ag} / \mathrm{AgNO}_{3}$ nonaqueous reference electrode. Representative cyclic voltammograms for $\mathbf{5 , 6}$, $\mathbf{7}$, and $\mathbf{8}$ are shown in Figure 4. No discernible oxidative waves were detected, owing to the electron-deficient nature of the compounds. On the other hand, the reduction of the azine (qui-

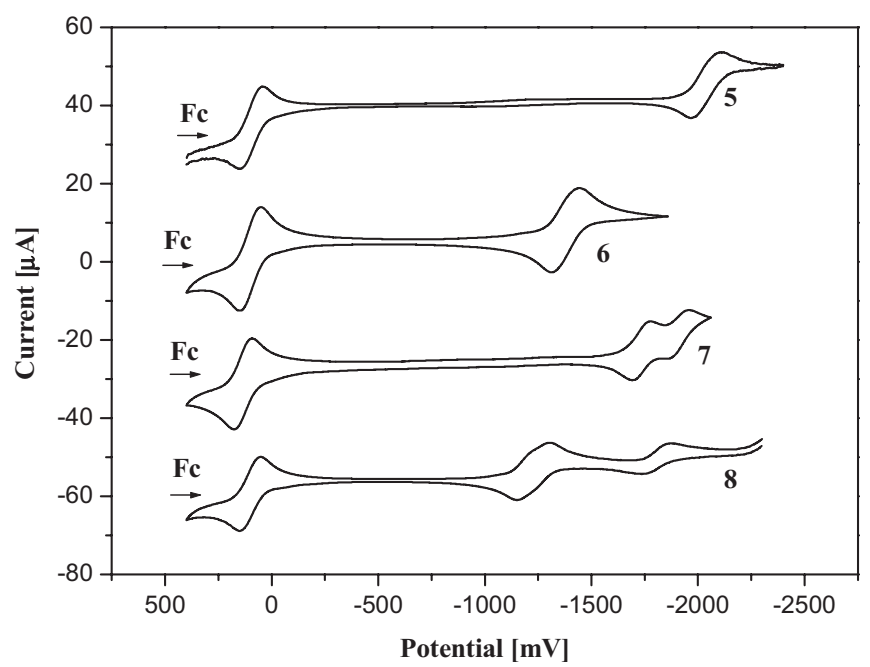

Figure 4. Cyclic voltammograms of 5-8 measured in dimethylformamide (DMF). All the potentials are reported relative to ferrocene, which was used as the internal standard in each experiment. The ferrocene oxidation potential was located at $+100 \mathrm{mV}$ relative to the $\mathrm{Ag} / \mathrm{AgNO}_{3}$ nonaqueous reference electrode.

noxaline or pyrazine) segment in the compounds was prominent, and was identified as a reversible, two-electron redox process. This reduction potential shifts anodically as the acceptor strength of the molecule increases. For example, the reduction potentials of $\mathbf{6}\left(E_{\mathrm{p}}=-1479 \mathrm{mV}\right)$ and $8\left(E_{\mathrm{p}}=-1330 \mathrm{mV}\right)$ shift anodically relative to those of $\mathbf{5}\left(E_{\mathrm{p}}=-2134 \mathrm{mV}\right)$ and $\mathbf{7}$ $\left(E_{\mathrm{p}}=-1657 \mathrm{mV}\right)$, respectively, due to the presence of the two cyano substituents in each azine of the former. The reduction potentials of the azine segments also exhibited a dramatic anodic shift upon replacing the dibenzothiophene unit with the more electron-deficient dibenzothiophene-S,S-dioxide unit, i.e., $5\left(E_{\mathrm{p}}=-2134 \mathrm{mV}\right)$ versus $7\left(E_{\mathrm{p}}=-1657 \mathrm{mV}\right)$, and $\mathbf{6}$ $\left(E_{\mathrm{p}}=-1479 \mathrm{mV}\right)$ versus $8\left(E_{\mathrm{p}}=-1330 \mathrm{mV}\right)$. An additional oneelectron reduction wave at more-negative potential $\left(E_{\mathrm{p}}=-2062\right.$ and $\left.-1914 \mathrm{mV}\right)$ is likely due to the reduction of the dioxide core. The capability of $\mathbf{7}$ and $\mathbf{8}$ to form trianions may be due to non-coplanarity between the dibenzothiophene-S,Sdioxide core (see below) and the azines, which reduces the electronic repulsion between them.

The first reduction potentials were used to determine the lowest unoccupied molecular orbital (LUMO) energy levels. Ferrocene served as the internal standard for calibrating the potential and calculating the highest occupied molecular orbital (HOMO) levels $(-4.8 \mathrm{eV}) \cdot{ }^{[17]}$ The cyclic voltammograms (see above) of the compounds were used to estimate the LUMO energy level by comparison with ferrocene $(-4.8 \mathrm{eV}) .^{[17]}$ These data, together with absorption spectra, were then used to obtain the HOMO energy levels of the compounds (Table 1, Fig. 5).
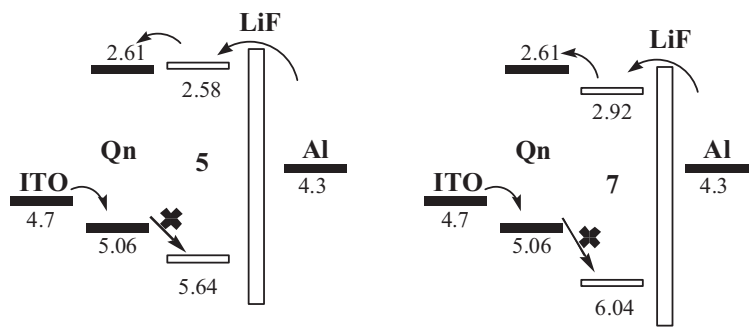

Figure 5. The relative energy alignments of the materials in the device. ITO: indium tin oxide.

\subsection{Charge-Transport Properties}

Carrier-transport properties of 2,3-bis[4-( $N$-phenyl-9-ethyl-3carbazolylamino)phenyl]quinoxaline (Qn, Scheme 2), 5, and $\mathbf{7}$ were investigated by the time-of-flight (TOF) transient photocurrent technique ${ }^{[18]}$ at room temperature. Figure $6 a$ shows a representative TOF transient for holes of $\mathbf{Q n}$, which reveals the slightly dispersive hole-transport characteristics of Qn. In the double-logarithmic representation (Fig. 6a, inset), the carrier-transit time, $t_{\mathrm{T}}$, needed for determining carrier mobilities can be clearly evaluated from the intersection point of two asymptotes. In contrast, TOF transients for electrons of $\mathbf{Q n}$ are highly dispersive, and no clear transit time could be resolved, even in the double logarithmic representation. The hole mobilities of Qn thus determined are shown in Figure $6 \mathrm{~b}$ as a function of the electric field. The field dependence of hole mobilities of Qn follows the nearly universal Poole-Frenkel relationship: $\mu \propto \exp \left(\beta E^{1 / 2}\right)$, where $\beta$ is the Poole-Frenkel factor and $E^{1 / 2}$ is the square root of the electric field ${ }^{[19]}$ Hole mobilities of $\mathbf{Q n}$ are in the range of $10^{-5}-10^{-4} \mathrm{~cm}^{2} \mathrm{~V}^{-1} \mathrm{~s}^{-1}$, which is one to two orders of magnitude lower than those of the typical hole-transport material 1,4-bis(1-naphthylphenylamino)-biphenyl (NPB; ca. $\left.10^{-3} \mathrm{~cm}^{2} \mathrm{~V}^{-1} \mathrm{~s}^{-1}\right) \cdot{ }^{[20]}$ Such results indeed directly verify our previous observations that incorporating quinoxaline segments in hole-transporting triarylamine molecules appears to retard the hole-transport in materials. ${ }^{[21]}$

On the other hand, $\mathbf{5}$ and $\mathbf{7}$ show dispersive electron transport, as indicated by their representative TOF transients (Fig. 7a for electrons of 5, Fig. 7b for electrons of 7). Nevertheless, the $t_{\mathrm{T}}$ needed for determining carrier mobilities can be 

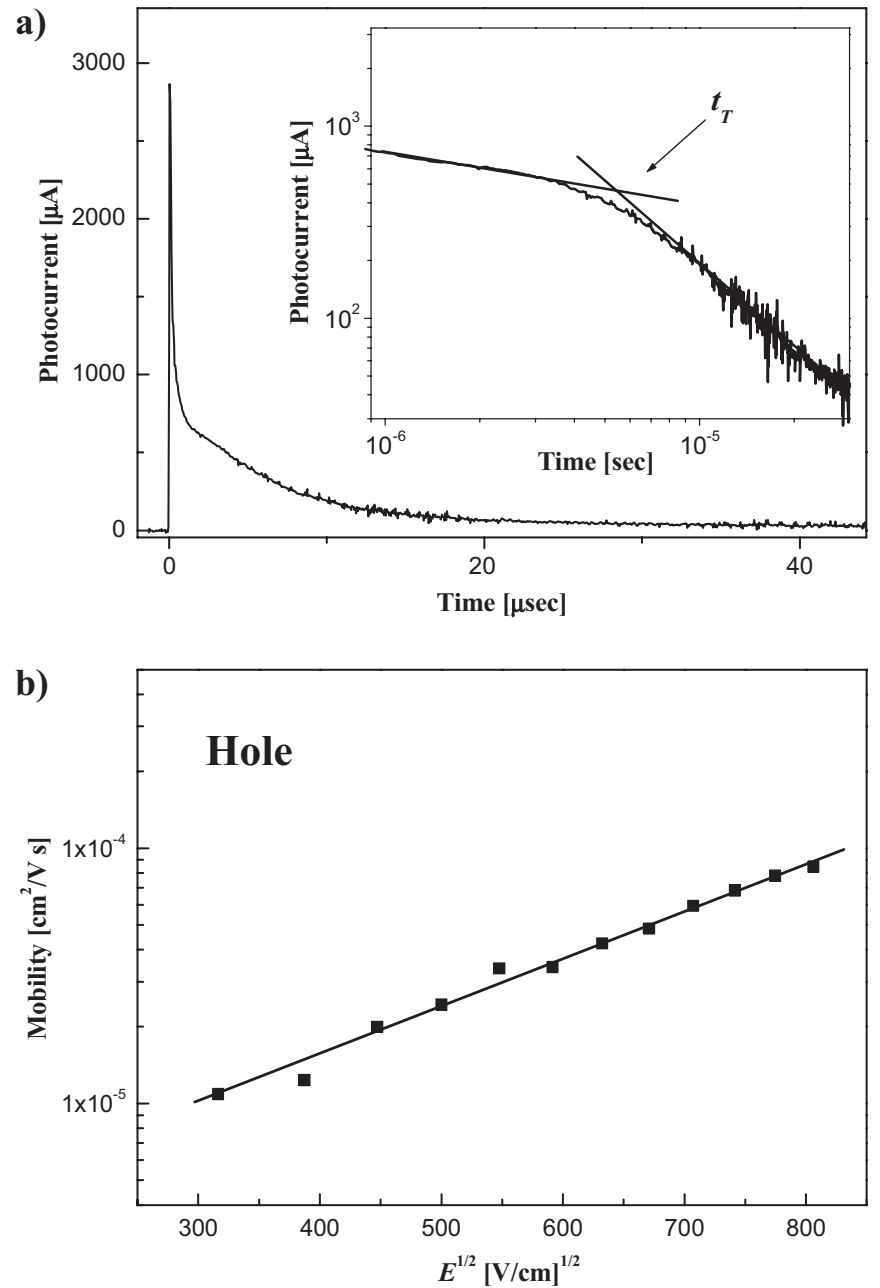

Figure 6. TOF transients for Qn $\left(2.0 \mu \mathrm{m}\right.$ thick): a) hole, $E=6.0 \times 10^{5} \mathrm{~V} \mathrm{~cm}^{-1}$. Inset: double logarithmic plot. b) Hole mobilities versus $E^{1 / 2}$ for $\mathbf{Q n}$.

clearly evaluated from the intersection point of two asymptotes in the double logarithmic representations (Fig. 7a and b, insets). In contrast, hole transport for $\mathbf{5}$ and $\mathbf{7}$ is highly dispersive, and no clear $t_{\mathrm{T}}$ could be extracted from the TOF transients. The electron mobilities of $\mathbf{5}$ and $\mathbf{7}$ as a function of the electric field are shown in Figure 7c, where again the Poole-Frenkel relationship is followed. Both compounds $\mathbf{5}$ and $\mathbf{7}$ have rather high electron mobilities $\left(10^{-4}-10^{-3} \mathrm{~cm}^{2} \mathrm{~V}^{-1} \mathrm{~s}^{-1}\right.$ and $2-5 \times 10^{-4} \mathrm{~cm}^{2} \mathrm{~V}^{-1} \mathrm{~s}^{-1}$, respectively) compared to those of the typical electron-transport material $\mathrm{Alq}_{3}\left(\right.$ ca. $\left.10^{-5} \mathrm{~cm}^{2} \mathrm{~V}^{-1} \mathrm{~s}^{-1}\right){ }^{[5 \mathrm{a}]}$

\subsection{Electroluminescent Properties}

In view of the low-lying LUMOs of compounds 5-8, we attempted to use them as the electron-transporting materials for OLEDs. However, the devices fabricated with $\mathbf{6}$ and $\mathbf{8}$ had very low efficiencies, and further device studies thus focused on $\mathbf{5}$ and 7. Double-layer devices using $\mathbf{5}$ and $\mathbf{7}$ as electron-transporting materials, and Qn as the hole-transporting and emitting materials, were fabricated with the structures: I) indium tin ox-
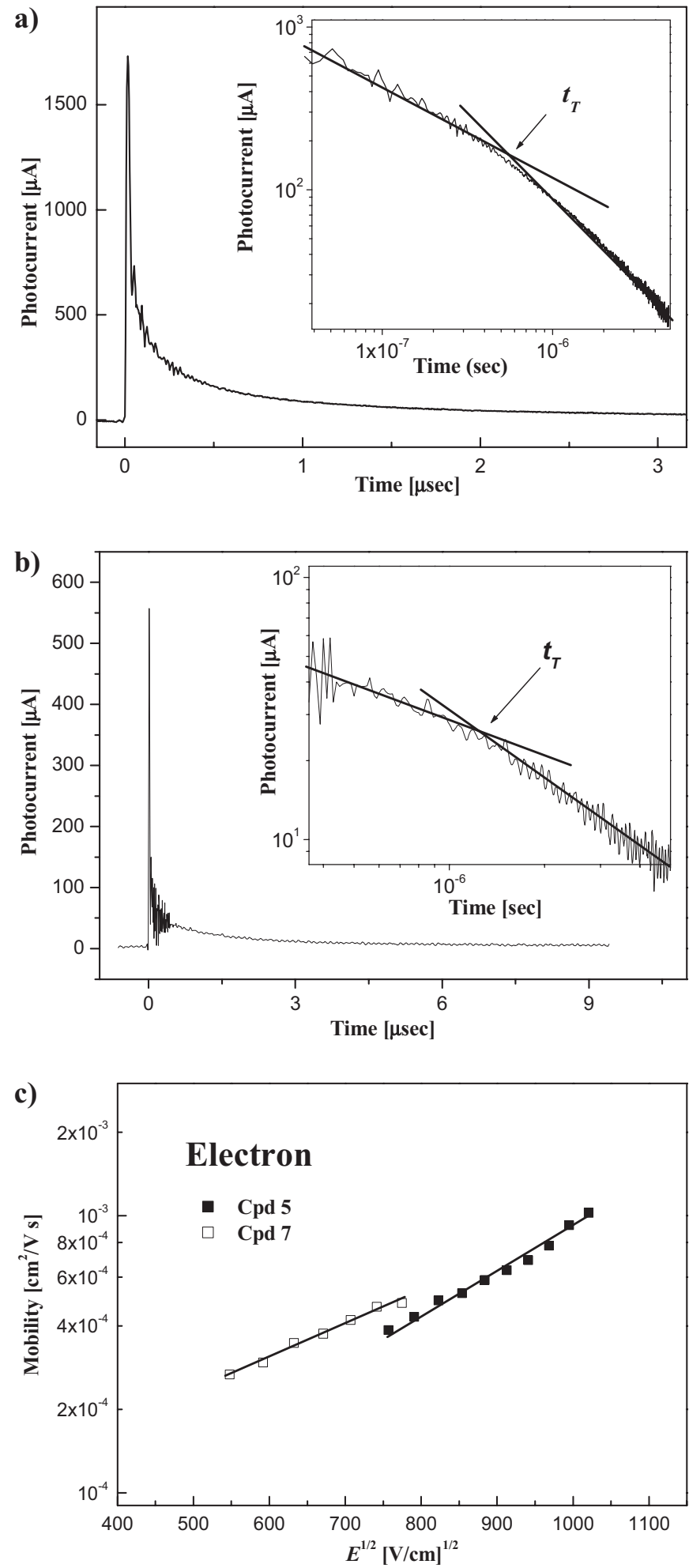

Figure 7. TOF transients for $\mathbf{5}(1.92 \mu \mathrm{m}$ thick) and $\mathbf{7}(2.0 \mu \mathrm{m}$ thick): a) $\mathbf{5}$, electron, $E=8.3 \times 10^{5} \mathrm{Vcm}^{-1}$; b) 7 ; electron, $E=5.0 \times 10^{5} \mathrm{Vcm}^{-1}$. Insets are the double logarithmic plots of (a) and (b). c) Electron mobilities versus $E^{1 / 2}$ for 5 and $\mathbf{7}$.

ide (ITO)/Qn (40 nm)/5 (40 nm)/LiF/Al; II) ITO/Qn (40 nm)/ $7(40 \mathrm{~nm}) / \mathrm{LiF} / \mathrm{Al}$. The compound $\mathbf{Q n}$ was chosen because it 
possesses appropriate HOMO $(5.06 \mathrm{eV})$ and LUMO $(2.61 \mathrm{eV})$ energy levels for hole injection from ITO and for electron injection from 5 (or 7), respectively. The performance parameters of both devices are summarized in Table 2. The current-

Table 2. EL data of the devices. CIE: Commission Internationale de l'Eclairage; FWHM: Full width at half maximum.

\begin{tabular}{|c|c|c|}
\hline & Device I & Device II \\
\hline turn-on voltage $[\mathrm{V}]$ & 3.3 & 2.4 \\
\hline$\lambda_{\mathrm{em}}[\mathrm{nm}]$ & 550 & 552 \\
\hline $\operatorname{CIE}(x, y)$ & $0.40,0.57$ & $0.42,0.55$ \\
\hline FWHM $[\mathrm{nm}]$ & 88 & 92 \\
\hline Brightness $[\mathrm{a}]\left[\mathrm{cd} \mathrm{m}^{-2}\right]$ (voltage $\left.[\mathrm{V}]\right)$ & $27485(15)$ & $8090(12.5)$ \\
\hline External quantum efficiency [a] [\%] & 2.11 & 0.38 \\
\hline Power efficiency [a] [lm W'-1] & 7.09 & 1.28 \\
\hline Current efficiency [a] $\left[\mathrm{cd} \mathrm{A}^{-1}\right]$ & 5.16 & 0.67 \\
\hline Brightness $[\mathrm{b}]\left[\mathrm{cd} \mathrm{m}^{-2}\right]$ & 4928 & 1268 \\
\hline External quantum efficiency [b] [\%] & 1.41 & 0.38 \\
\hline Power efficiency [b] [lm W-1] & 4.94 & 1.27 \\
\hline Current efficiency $[\mathrm{b}]\left[\mathrm{cd} \mathrm{A}{ }^{-1}\right]$ & 1.62 & 0.61 \\
\hline
\end{tabular}

[a] Maximum value. [b] At a current density of $100 \mathrm{~mA} \mathrm{~cm}^{-2}$. The structure of device I: ITO/Qn $(40 \mathrm{~nm}) / 5(40 \mathrm{~nm}) / \mathrm{LiF} / \mathrm{Al}$. The structure of device II: ITO/Qn $(40 \mathrm{~nm}) / 7(40 \mathrm{~nm}) / \mathrm{LiF} / \mathrm{Al}$.

voltage-luminance $(I-V-L)$ characteristics are shown in Figure 8 . The electroluminescence (EL) spectra remain the same in the voltage range of 6.0 to $12.0 \mathrm{~V}$. Figure 9 depicts the EL spectra of devices I and II. Both devices show yellow emission, characteristic of Qn $\left(\lambda_{\max }\right.$ ca. $\left.550 \mathrm{~nm}\right)$, indicating emission from the Qn layer. Such characteristics (i.e., confinement of carriers and excitons in Qn) may be due to efficient electron transport and possibly hole-blocking (see relative energy levels in Fig. 5) of 5 and 7, and the retarded hole transport of Qn due to incorporation of the quinoxaline moiety into the hole-transport arylamino derivative.

Device I appears to have much better performance parameters, such as external quantum efficiency, power efficiency, and current efficiency, than device II. At a current density of

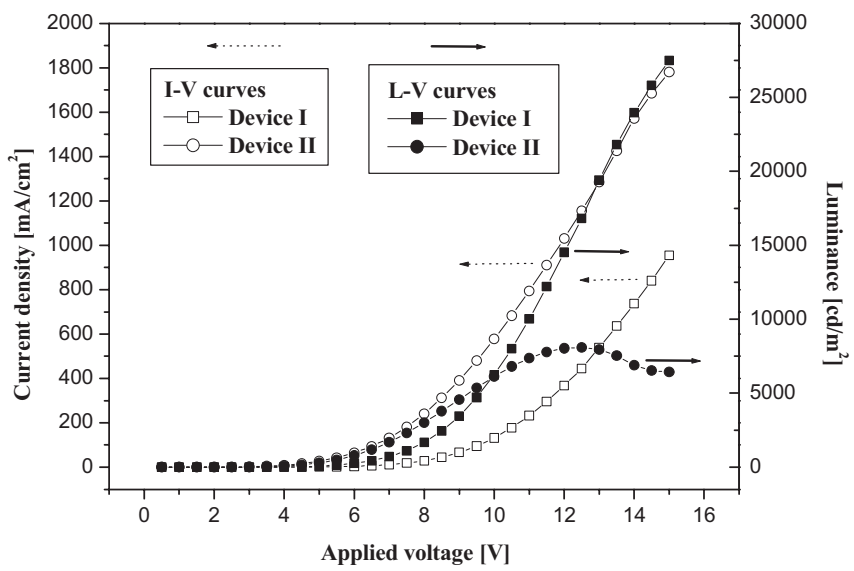

Figure 8. Current density versus applied electric voltage versus luminance characteristics of devices I and II.

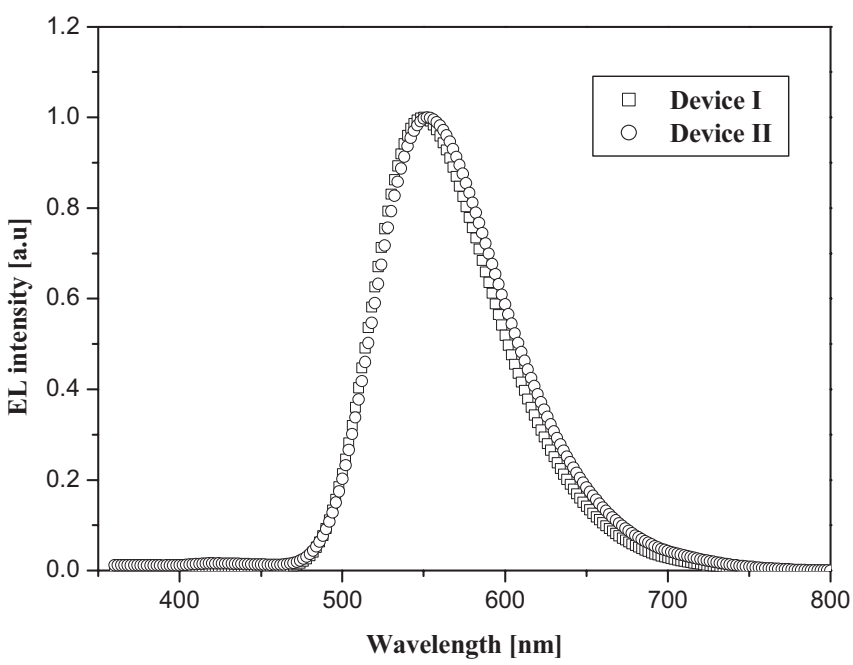

Figure 9. The EL spectra of devices I and II.

$100 \mathrm{~mA} \mathrm{~cm}^{-2}$, device I also performs better: the external quantum efficiency of $\mathrm{I}$ is $1.41 \%$, while II is $0.38 \%$; the power efficiency of I is $4.94 \%$, while II is $1.27 \%$; and the current efficiency of $\mathrm{I}$ is $1.62 \%$, while II is $0.61 \%$. Several factors, including the interfacial energy barriers (e.g., organic/electrode, organic/ organic etc.), can contribute to differences in the device performances of devices I and II. For instance, at a particular voltage, the smaller current density in I than in II is possibly due to the larger barrier for electron injection between the electron-transporting layer (ETL) and the cathode. The much inferior efficiency of device II compared to I, however, is believed to be mainly due to the formation of a weakly emissive exciplex ${ }^{[22]}$ between $\mathbf{Q n}$ and 7 in device II. The formation of such an exciplex is supported by the following observations: i) The PL spectrum of the 1:1 blend film of $\mathbf{Q n} / \mathbf{7}$ is broader and redshifted compared to that of the Qn film, while the PL spectrum of the 1:1 blend film of $\mathbf{Q n} / \mathbf{5}$ is almost superimposable on that of the Qn film (Fig. 10). The EL spectrum of device II is also slightly broadened in the long wavelength portion compared to the EL spectrum of device I and the PL spectra of the Qn film; ii) Upon excitation at the Qn absorption wavelength $(430 \mathrm{~nm})$, the relative emission quantum yield of the three films, Qn, 1:1 Qn/5 blend, and 1:1 Qn/7 blend, is 100:85:7. The greater tendency to form an exciplex between $\mathbf{Q n}$ and 7 may be due to the smaller energy difference between the ionization potential of Qn and the electron affinity of $\mathbf{7}$ compared to that between Qn and 5.

\section{Conclusions}

We have synthesized a series of new OLED materials with a 2,8-disubstituted dibenzothiophene or dibenzothiophene-S,Sdioxide core and peripheral quinoxaline/pyrazine units. The introduction of azine (quinoxaline/pyrazine) segments to dibenzothiophene and dibenzothiophene- $S, S$-dioxide derivatives increases the thermal stability of the compounds. These com- 


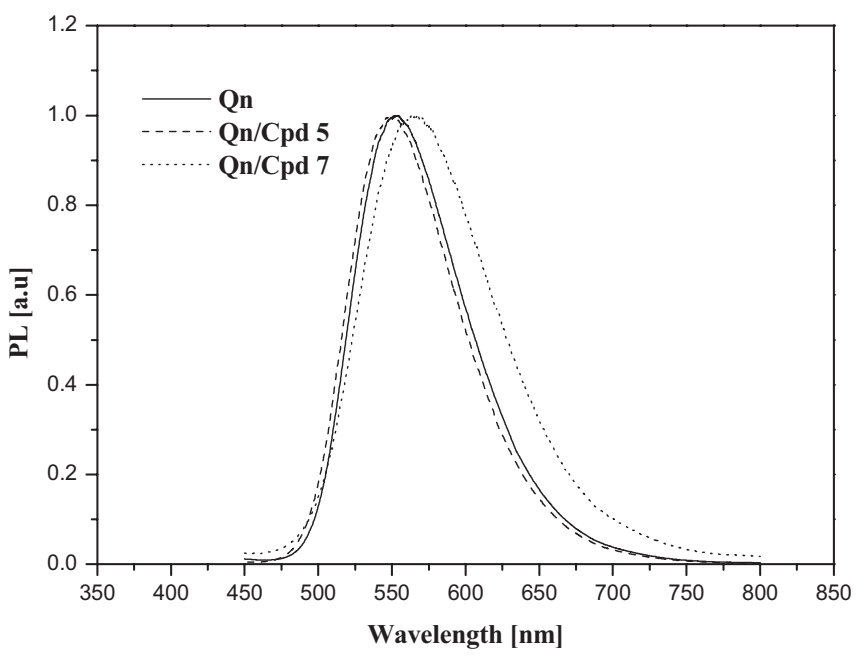

Figure 10. PL spectra of Qn, 1:1 Qn/5 blend, and 1:1 Qn/7 blend films.

pounds exhibit rather high electron mobilities, and OLEDs with promising performances can be fabricated by using these compounds as electron-transporting materials. Further modification of these n-type electroluminescent materials is ongoing.

\section{Experimental}

General Information: Unless otherwise specified, all the reactions were carried out under nitrogen using standard Schlenk techniques. Solvents were dried by standard procedures. All column chromatography was performed using silica gel (230-400 mesh, SiliCycle Inc.) as the stationary phase. Phenylacetylene, iodine, and triphenylphosphine $\left(\mathrm{PPh}_{3}\right)$ were purchased from Aldrich. Diaminomaleonitrile and cuprous iodide were purchased from Acros. 4,5-Dimethyl-1,2-phenylenediamine was purchased from TCI. The starting materials 2,8-dibromobenzothiophene, 2,8-dibromobenzothiophene-S,S-dioxide, and $\mathrm{PdCl}_{2}\left(\mathrm{PPh}_{3}\right)_{2}$ were prepared according to literature procedures [23]. The ${ }^{1} \mathrm{H}$ NMR spectra were recorded on a Bruker AMX 400 spectrometer. Electronic absorption spectra were measured in various solvents using a Cary 50 Probe UV-vis spectrophotometer. Emission spectra were recorded by a Hitachi F-4500 fluorescence spectrometer. Cyclic voltammetry experiments were performed with a BAS-100 electrochemical analyzer. All measurements were carried out at room temperature with a conventional three-electrode configuration consisting of platinum working and auxiliary electrodes and a non-aqueous $\mathrm{Ag}$ / $\mathrm{AgNO}_{3}$ reference electrode. The $E_{1 / 2}$ values were determined as $1 / 2\left(E_{\mathrm{p}}{ }^{\mathrm{a}}+E_{\mathrm{p}}{ }^{\mathrm{c}}\right)$, where $E_{\mathrm{p}}{ }^{\mathrm{a}}$ and $E_{\mathrm{p}}{ }^{\mathrm{c}}$ are the anodic and cathodic peak potentials, respectively. The solvent in all experiments was $N, N$-dimethylformamide and the supporting electrolyte was $0.1 \mathrm{~m}$ tetrabutylammonium perchlorate. DSC measurements were carried out using a PerkinElmer 7 series thermal analyzer at a heating rate of $10^{\circ} \mathrm{C} \mathrm{min}{ }^{-1}$ and cooling at $30^{\circ} \mathrm{C} \mathrm{min}^{-1}$. TGA measurements were performed on a Perkin-Elmer TGA7 thermal analyzer. Mass spectra (fast atom bombardment mass spectrometry, FAB-MS) were recorded on a JMS-700 double focusing mass spectrometer (JEOL, Tokyo, Japan). Elemental analyses were performed on a Perkin-Elmer $2400 \mathrm{CHN}$ analyzer.

Synthesis of the 2,8-Diethynyl Derivatives (1 and 2): Compounds 2,8di(2-phenyl-1-ethynyl)dibenzo[b,d]thiophene (1) and 2,8-di(2-phenyl1 -ethynyl)-5H-5 $\lambda^{6}$-dibenzothiophene-S,S-dioxide (2) were synthesized by similar procedures, as described bellow. 2,8-Dibromo starting material $(3.0 \mathrm{mmol}), \mathrm{Pd}\left(\mathrm{PPh}_{3}\right)_{2} \mathrm{Cl}_{2}(1 \mathrm{mmol} \%$ per halogen atom $), \mathrm{CuI}$ ( $3 \mathrm{mmol} \%$ per halogen atom), $\mathrm{PPh}_{3}(1 \mathrm{mmol} \%$ per halogen atom), phenylacetylene (2 equiv, $6.0 \mathrm{mmol}$ ), and diisopropylamine $(70 \mathrm{~mL})$ were charged sequentially into a two-neck flask under nitrogen and heated to reflux for $16 \mathrm{~h}$. The volatile compounds were removed under vacuum, and the resulting solid was extracted into diethyl ether. The organic extract was washed with brine solution, dried over anhydrous $\mathrm{MgSO}_{4}$, and evaporated to leave a white solid. It was further purified by recrystallization from $\mathrm{CH}_{2} \mathrm{Cl}_{2}$ and $\mathrm{n}$-hexane.

Synthesis of the Dione Derivatives (3 and 4): Compounds 1-[8-(2oxo-2-phenylacetyl)dibenzo[ $b, d]$ thiophen-2-yl]-2-phenyl-1,2-ethanedione $(3)$ and 2,8-di(2-oxo-2-phenylacetyl)-5H-5 $l^{6}$-dibenzo- $[b, d]$ thiophene-5,5-dione (4) were synthesized by similar procedures, as described below. A two-necked round-bottomed flask was charged with dialkyne ( $2 \mathrm{mmol}), \mathrm{I}_{2}(2.0 \mathrm{~g}, 8 \mathrm{mmol}$ per alkyne), and dimethyl sulfoxide (DMSO; $50 \mathrm{~mL}$ ). The reaction mixture was heated to $155^{\circ} \mathrm{C}$ for $20 \mathrm{~h}$. After cooling, the solution was poured into $1 \%$ aqueous $\mathrm{Na}_{2} \mathrm{~S}_{2} \mathrm{O}_{3}$ $(160 \mathrm{~mL})$. A white solid precipitated, which was filtered, washed with water, and dried. Analytically pure product was isolated without further purification.

Synthesis of the Diquinoxaline/Dipyrazine Derivatives $(\mathbf{5}, \mathbf{6}, \mathbf{7}$, and 8): Compounds 2-[8-(6,7-dimethyl-3-phenyl-2-quinoxalinyl)dibenzo[b,d]thiophen-2-yl]-6,7-dimethyl-3-phenylquinoxaline (5), 5-[8-(5,6dicyano-3-phenyl-2-pyrazinyl)dibenzo[ $b, d]$ thiophen-2-yl]-6-phenyl-2,3pyrazinedicarbonitrile (6), 2,8-di(6,7-dimethyl-3-phenyl-2-quinoxalinyl)-5H-5 $\lambda^{6}$-dibenzo[ $\left.b, d\right]$ thiophene-5,5-dione (7), and 5-[8-(5,6-dicyano-3-phenyl-2-pyrazinyl)-5,5-dioxo-5 $H$-5 $l^{6}$-dibenzo[ $\left.b, d\right]$ thiophen-2-yl $]$ 6-phenyl-2,3-pyrazinedicarbonitrile (8) were synthesized by similar procedures, as described below. A two-necked round-bottomed flask was charged with diamine $(2.0 \mathrm{mmol})$, bis-dione $(1.0 \mathrm{mmol})$, and $\mathrm{CHCl}_{3}$ /ethanol $(50 \mathrm{~mL}$; ratio=1:2). Two drops of sulfuric acid were then added to initiate the reaction. The mixture was refluxed for $16 \mathrm{~h}$. After cooling, the solvent was removed by Dean-Stark distillation. The resulting suspension was filtered, washed with methanol, and dried. The residue was dissolved in $\mathrm{CH}_{2} \mathrm{Cl}_{2}$ and passed through $2 \mathrm{~cm}$ Celite. The solution was pumped dry, and the solid was sublimed to provide a powdery product.

Compound (1): White solid. Yield $=92 \%(945 \mathrm{mg}) .{ }^{1} \mathrm{H}$ NMR (acetone- $\left.d_{6}\right) \delta$ [ppm]: 7.34-7.39 (m, 6H, m-, $\left.p-\mathrm{C}_{6} H_{5}\right), 7.57(\mathrm{~d}, 4 \mathrm{H}$, $\left.J=7.5 \mathrm{~Hz}, o-\mathrm{C}_{6} H_{5}\right), 7.62\left(\mathrm{dd}, 2 \mathrm{H}, J_{1}=8.3 \mathrm{~Hz}, J_{2}=1.5 \mathrm{~Hz}, \mathrm{C}_{6} H_{3}\right), 7.81$ $\left(\mathrm{d}, 2 \mathrm{H}, J=8.3 \mathrm{~Hz}, \mathrm{C}_{6} H_{3}\right), 8.33\left(\mathrm{~d}, 2 \mathrm{H}, J=1.5 \mathrm{~Hz}, \mathrm{C}_{6} H_{3}\right)$. Electron-impact mass spectrometry (EIMS) $(\mathrm{m} / \mathrm{e}): 384\left(\mathrm{M}^{+}\right)$. Anal. calcd. for $\mathrm{C}_{28} \mathrm{H}_{16} \mathrm{~S}: \mathrm{C}, 87.47 ; \mathrm{H}, 4.19$. Found: $\mathrm{C}, 87.78 ; \mathrm{H}, 4.23$.

Compound (2): White solid. Yield $=90 \% \quad(998 \mathrm{mg}) .{ }^{1} \mathrm{H}$ NMR $\left(\mathrm{CDCl}_{3}\right) \delta[\mathrm{ppm}]: 7.37-7.39\left(\mathrm{~m}, 6 \mathrm{H}, m-, p-\mathrm{C}_{6} H_{5}\right), 7.55-7.57(\mathrm{~m}, 4 \mathrm{H}$, $\left.o-\mathrm{C}_{6} H_{5}\right), 7.66\left(\mathrm{dd}, 2 \mathrm{H}, J_{1}=8.0 \mathrm{~Hz}, J_{2}=1.3 \mathrm{~Hz}, \mathrm{C}_{6} H_{3}\right), 7.79(\mathrm{~d}, 2 \mathrm{H}$, $\left.J=8.0 \mathrm{~Hz}, \mathrm{C}_{6} H_{3}\right), 7.95\left(\mathrm{~d}, 2 \mathrm{H}, J=1.3 \mathrm{~Hz}, \mathrm{C}_{6} H_{3}\right)$. EIMS $(\mathrm{m} / \mathrm{e}): 416$ $\left(\mathrm{M}^{+}\right)$. Anal. calcd. for $\mathrm{C}_{28} \mathrm{H}_{16} \mathrm{O}_{2} \mathrm{~S}: \mathrm{C}, 80.75 ; \mathrm{H}, 3.87$. Found: $\mathrm{C}, 81.10 ; \mathrm{H}$, 3.91 .

Compound (3): Brown solid. Yield $=80 \%(717 \mathrm{mg}) .{ }^{1} \mathrm{H}$ NMR (acetone- $\left.d_{6}\right) \delta[\mathrm{ppm}]: 7.62\left(\mathrm{t}, 4 \mathrm{H}, J=8.0 \mathrm{~Hz}, m-\mathrm{C}_{6} H_{5}\right), 7.77(\mathrm{t}, 2 \mathrm{H}$, $\left.J=6.8 \mathrm{~Hz}, p-\mathrm{C}_{6} H_{5}\right), 7.21\left(\mathrm{~d}, 4 \mathrm{H}, J=7.2 \mathrm{~Hz}, o-\mathrm{C}_{6} H_{5}\right), 8.18(\mathrm{dd}, 2 \mathrm{H}$ $\left.J_{1}=8.5 \mathrm{~Hz}, J_{2}=1.6 \mathrm{~Hz}, \mathrm{C}_{6} H_{3}\right), 8.32\left(\mathrm{~d}, 2 \mathrm{H}, J=8.5 \mathrm{~Hz}, \mathrm{C}_{6} H_{3}\right), 9.09(\mathrm{~d}$, $\left.2 \mathrm{H}, J=1.6 \mathrm{~Hz}, \mathrm{C}_{6} H_{3}\right)$. FABMS $(m / e): 449\left(\mathrm{M}^{+}\right)$. Anal. calcd. for $\mathrm{C}_{28} \mathrm{H}_{16} \mathrm{O}_{4} \mathrm{~S}: \mathrm{C}, 74.98 ; \mathrm{H}, 3.60$. Found: $\mathrm{C}, 75.02 ; \mathrm{H}, 3.71$.

Compound (4): White solid. Yield $=83 \% \quad(797 \mathrm{mg}) .{ }^{1} \mathrm{H}$ NMR $\left(\mathrm{CDCl}_{3}\right) \delta[\mathrm{ppm}]: 7.56\left(\mathrm{t}, 4 \mathrm{H}, J=7.7 \mathrm{~Hz}, m-\mathrm{C}_{6} H_{5}\right), 7.71(\mathrm{t}, 2 \mathrm{H}$, $\left.J=7.7 \mathrm{~Hz}, \quad p-\mathrm{C}_{6} H_{5}\right), 7.99\left(\mathrm{~m}, 6 \mathrm{H}, o-\mathrm{C}_{6} H_{5}, \mathrm{C}_{6} H_{3}\right), 8.16(\mathrm{dd}, 2 \mathrm{H}$, $\left.J_{1}=8.0 \mathrm{~Hz}, J_{2}=1.3 \mathrm{~Hz}, \mathrm{C}_{6} H_{3}\right), 8.49\left(\mathrm{~d}, 2 \mathrm{H}, J=1.3 \mathrm{~Hz}, \mathrm{C}_{6} H_{3}\right)$. FABMS (m/e): $481\left(\mathrm{M}^{+}\right)$. Anal. calcd. for $\mathrm{C}_{28} \mathrm{H}_{16} \mathrm{O}_{6} \mathrm{~S}: \mathrm{C}, 69.99 ; \mathrm{H}, 3.36$. Found: C, $70.10 ; \mathrm{H}, 3.39$.

Compound (5): White solid. Yield $=60 \%(470 \mathrm{mg}) .{ }^{1} \mathrm{H}$ NMR (acetone- $\left.d_{6}\right) \delta[\mathrm{ppm}]: 2.52\left(\mathrm{~s}, 12 \mathrm{H}, \mathrm{CH}_{3}\right), 7.28-7.32\left(\mathrm{~m}, 6 \mathrm{H}, o-, p-\mathrm{C}_{6} H_{5}\right)$, $7.41\left(\mathrm{dd}, 2 \mathrm{H}, J_{1}=8.4 \mathrm{~Hz}, J_{2}=1.3 \mathrm{~Hz}, \mathrm{C}_{6} H_{3}\right), 7.50-7.53(\mathrm{~m}, 4 \mathrm{H}, m-$ $\left.\mathrm{C}_{6} H_{5}\right), 7.68\left(\mathrm{~d}, 2 \mathrm{H}, J=8.4 \mathrm{~Hz}, \mathrm{C}_{6} H_{3}\right), 7.94\left(\mathrm{~s}, 4 \mathrm{H}, \mathrm{C}_{6} H_{2}\right), 8.41(\mathrm{~d}, 2 \mathrm{H}$, $\left.J=1.3 \mathrm{~Hz}, \mathrm{C}_{6} H_{3}\right)$. FABMS $(m / e): 649\left(\mathrm{M}^{+}\right)$. Anal. calcd for $\mathrm{C}_{44} \mathrm{H}_{32} \mathrm{~N}_{4} \mathrm{~S}$ : C, 81.45; H, 4.97; N, 8.64. Found: C, 81.22; H, 5.01; N, 8.60.

Compound (6): Yellow solid. Yield $=48 \% \quad(450 \mathrm{mg}) .{ }^{1} \mathrm{H}$ NMR $\left(\mathrm{CDCl}_{3}\right) \delta[\mathrm{ppm}]: 7.43\left(\mathrm{t}, 4 \mathrm{H}, J=7.4 \mathrm{~Hz}, m-\mathrm{C}_{6} H_{5}\right), 7.51(\mathrm{t}, 2 \mathrm{H}$, $\left.J=7.4 \mathrm{~Hz}, p-\mathrm{C}_{6} H_{5}\right), 7.60-7.66\left(\mathrm{~m}, 6 \mathrm{H}, o-\mathrm{C}_{6} H_{5}, \mathrm{C}_{6} H_{3}\right), 8.01(\mathrm{~d}, 2 \mathrm{H}$, $\left.J=8.4 \mathrm{~Hz}, \mathrm{C}_{6} H_{3}\right), 8.53\left(\mathrm{~d}, 2 \mathrm{H}, J=1.4 \mathrm{~Hz}, \mathrm{C}_{6} H_{3}\right)$. FABMS $(m / e): 592$ $\left(\mathrm{M}^{+}\right)$. Anal. calcd. for $\mathrm{C}_{36} \mathrm{H}_{16} \mathrm{~N}_{8} \mathrm{~S}$ : C, 72.96; H, 2.72; N, 18.91. Found: $\mathrm{C}$, $72.87 ; \mathrm{H}, 2.62 ; \mathrm{N}, 18.82$. 
Compound (7): White solid. Yield $=62 \% \quad(560 \mathrm{mg}) .{ }^{1} \mathrm{H}$ NMR $\left(\mathrm{CDCl}_{3}\right) \delta[\mathrm{ppm}]: 2.53\left(\mathrm{~s}, 12 \mathrm{H}, \mathrm{CH}_{3}\right), 7.35-7.38\left(\mathrm{~m}, 6 \mathrm{H}, o-, p-\mathrm{C}_{6} H_{5}\right)$, $7.46-7.51\left(\mathrm{~m}, 6 \mathrm{H}, \mathrm{C}_{6} H_{3}, m-\mathrm{C}_{6} H_{5}\right), 7.66\left(\mathrm{~d}, 2 \mathrm{H}, J=8.0 \mathrm{~Hz}, \mathrm{C}_{6} H_{3}\right), 7.93$ $\left(\mathrm{s}, 2 \mathrm{H}, \mathrm{C}_{6} H_{2}\right), 7.95\left(\mathrm{~s}, 2 \mathrm{H}, \mathrm{C}_{6} H_{2}\right), 8.09\left(\mathrm{~s}, 2 \mathrm{H}, \mathrm{C}_{6} H_{3}\right)$. FABMS $(m / e)$ : $681\left(\mathrm{M}^{+}\right)$. Anal. calcd. for $\mathrm{C}_{44} \mathrm{H}_{32} \mathrm{~N}_{4} \mathrm{O}_{2} \mathrm{~S}: \mathrm{C}, 77.62 ; \mathrm{H}, 4.74 ; \mathrm{N}, 8.23$. Found: C, 77.60; H, 4.78; N, 8.36.

Compound $(\boldsymbol{8})$ : White solid. Yield $=51 \% \quad(426 \mathrm{mg}) .{ }^{1} \mathrm{H}$ NMR $\left(\mathrm{CDCl}_{3}\right) \delta[\mathrm{ppm}]: 7.45\left(\mathrm{t}, 4 \mathrm{H}, J=8.2 \mathrm{~Hz}, m-\mathrm{C}_{6} H_{5}\right), 7.54-7.57(\mathrm{~m}, 8 \mathrm{H}$, $\left.\mathrm{C}_{6} \mathrm{H}_{3}, o-, p-\mathrm{C}_{6} H_{5}\right), 7.73\left(\mathrm{~d}, 2 \mathrm{H}, J=8.1 \mathrm{~Hz}, \mathrm{C}_{6} H_{3}\right), 8.10\left(\mathrm{~s}, 2 \mathrm{H}, \mathrm{C}_{6} H_{3}\right) . \mathrm{EI}$ MS (m/e): $624\left(\mathrm{M}^{+}\right)$. Anal. calcd. for $\mathrm{C}_{36} \mathrm{H}_{16} \mathrm{~N}_{8} \mathrm{O}_{2} \mathrm{~S}: \mathrm{C}, 69.22 ; \mathrm{H}, 2.58 ; \mathrm{N}$, 17.94. Found: C, $69.28 ; \mathrm{H}, 2.35 ; \mathrm{N}, 18.01$.

Structural Determination of $7 \cdot \mathrm{CH}_{2} \mathrm{Cl}_{2}$ : Orange prismatic crystals of 7. $\mathrm{CH}_{2} \mathrm{Cl}_{2}$ were grown from $\mathrm{CH}_{2} \mathrm{Cl}_{2} / \mathrm{n}$-hexane at room temperature. Data collection was carried out on an Nonius KappaCCD and Enrafnonius CAD4 diffractometer at room temperature. Mo K $\alpha$ radiation $(\lambda=0.71073 \AA)$ was used for the crystal. The unit-cell parameters were obtained by a least-squares fit to the automatically centered settings for reflections. Data were collected in $\omega / 2 \theta$ scan mode. Corrections were made for Lorentz and polarization effects. All calculations were performed using the SHELX software package by a direct method and refined by a full-matrix least-squares method on $F^{2}(F$ : structure factor). A crystal of dimensions $0.16 \mathrm{~mm} \times 0.1 \mathrm{~mm} \times 0.1 \mathrm{~mm}$ was mounted on a glass fiber covered with epoxy. Relevant crystal data are summarized in Table S1 (Supporting Information). The orthorhombic space group $P 1$ was determined from the systematic absence of specific reflections; successful refinement of the structure confirmed the space group assignment.

Crystallographic data (excluding structure factors) for the structure reported in this paper have been deposited with the Cambridge Crystallographic Data Centre as supplementary publication no. CCDC290060.

LED Fabrication and Measurement: The hole-transporting and emitting material Qn was prepared by literature procedures [21], and was sublimed twice prior to use. Pre-patterned ITO substrates with an effective individual device area of $3.14 \mathrm{~mm}^{2}$ were cleaned as described in a previous report [24]. The thermal evaporation of organic materials was carried out following previously published procedures [18]. Double-layer EL devices were fabricated using compounds $\mathbf{5}$ or $\mathbf{7}$ as the electron-transporting layer and $\mathbf{Q n}$ as the hole-transporting and emitting layer. The devices were prepared by vacuum deposition of $40 \mathrm{~nm}$ of the hole-transporting layer, followed by $40 \mathrm{~nm}$ of $\mathbf{5}$ or $\mathbf{7}$. Inorganic $\mathrm{LiF}$ (1 nm thick) was then deposited as the buffer layer. Aluminum was finally deposited as the cathode $(150 \mathrm{~nm}) . I-V$ curves were measured in a Keithley 2400 Source Meter under the ambient environment. Light intensity was measured with a Newport 1835 Optical Meter.

TOF Mobility Measurements: The compounds Qn, 5, and 7 were purified by sublimation before use in subsequent analyses and device fabrication. The samples $\mathbf{x}(\mathbf{x}=\mathbf{Q n}, \mathbf{5}$, or 7) for the TOF measurement were prepared by vacuum deposition using the structure of: glass/Ag $(30 \mathrm{~nm}) /$ $\mathbf{x}($ ca. $2 \mu \mathrm{m}) / \mathrm{Al}(150 \mathrm{~nm})$ with an active area of $2 \mathrm{~mm} \times 2 \mathrm{~mm}$, as described in a previous report [18a,b]. A frequency-tripled Nd:YAG (yttrium aluminum garnet) laser $(355 \mathrm{~nm})$ with ca. $10 \mathrm{~ns}$ pulse duration was used for pulsed illumination through the semitransparent Ag. Under an applied dc bias, the transient photocurrent as a function of time was recorded with a digital storage oscilloscope. The TOF measurements were typically performed in a $10^{-5}$ Torr $(1$ Torr $=133.322 \mathrm{~Pa})$ vacuum chamber. Depending on the polarity of the applied bias $V$, selected photogenerated carriers (holes or electrons) were swept across the sample thickness $D$ with a transit time $t_{\mathrm{T}}$; the applied electric field $E$ is then $V / D$, and the carrier mobility is given by $\mu=D /\left(t_{\mathrm{T}} E\right)=D^{2} /\left(V t_{\mathrm{T}}\right)$.

Received: November 18, 2005 Final version: January 18, 2006 Published online: June 23, 2006

[1] a) R. F. Service, Science 1996, 273, 878. b) J. Shi, C. W. Tang, Appl Phys. Lett. 1997, 70, 1665. c) R. H. Friend, R. W. Gymer, A. B.
Holmes, J. H. Burroughes, R. N. Marks, C. Taliani, D. D. C. Bradley, D. A. Dos Santos, J. L. Brédas, M. Lögdlund, W. R. Salaneck, Nature 1999, 397, 121. d) M. T. Bernius, M. Inbasekaran, J. O'Brien, W. Wu, Adv. Mater. 2000, 12, 1737. e) I. S. Millard, Synth. Met. 2000, 111, 119.

[2] C. W. Tang, S. A. Van Slyke, Appl. Phys. Lett. 1987, 51, 913.

[3] J. H. Burroughes, D. D. C. Bradley, A. R. Brown, R. N. Marks, K. Mackay, R. H. Friend, P. L. Burn, A. B. Holmes, Nature 1990, 347 , 539.

[4] a) J. Li, C. Ma, J. Tang, C.-S. Lee, S. Lee, Chem. Mater. 2005, 17, 615 b) Z. H. Li, M. S. Wong, H. Fukutani, Y. Tao, Chem. Mater. 2005, 17, 5032. c) T.-H. Huang, W.-T. Whang, J. Y. Shen, J. T. Lin, J. Mater Chem. 2005, 15, 3233.

[5] a) A. P. Kulkarni, C. J. Tonzola, A. Babel, S. A. Jenekhe, Chem. Ma ter. 2004, 16, 4556. b) R. Pohl, V. A. Montes, J. Shinar, P. Anzenbacher, Jr., J. Org. Chem. 2004, 69, 1723.

[6] T. C. Wong, J. Kovac, C. S. Lee, L. S. Hung, S. T. Lee, Chem. Phys. Lett. 2001, 334, 61.

[7] a) J. Kido, Y. Okamoto, Chem. Rev. 2002, 102, 2357. b) H.-C. Yeh, R.-H. Lee, L.-H. Chan, T.-Y. J. Lin, C.-T. Chen, E. Balasubramaniam, Y.-T. Tao, Chem. Mater. 2001, 13, 2788. c) T. Hadizad, J. Zhang, Z. Y. Wang, T. C. Gorjanc, C. Py, Org. Lett. 2005, 7, 795.

[8] a) C. Adachi, T. Tsutsui, S. Saito, Appl. Phys. Lett. 1989, 55, 1489 b) J. Pommerehne, H. Vestweber, W. Guss, R. F. Mahrt, H. Bassler, M. Porsch, J. Daub, Adv. Mater. 1995, 7, 55.

[9] C. Adachi, T. Tsutsui, S. Saito, Appl. Phys. Lett. 1990, 56, 799.

[10] a) J. Bettenhausen, M. Greczmiel, M. Jandke, P. Strohriegl, Synth. Met. 1997, 91, 223. b) P. Karastatiris, J. A. Mikroyannidis, I. K. Spiliopoulos, A. P. Kulkarni, S. A. Jenekhe, Macromolecules 2004, 37, 7867. c) F.-M. Hwang, H.-Y. Chen, P.-S. Chen, C.-S. Liu, Y. Chi, C.-F. Shu, F.-I. Wu, P.-T. Chou, S.-M. Peng, G.-H. Lee, Inorg. Chem. 2005, 44, 1344. d) J.-F. Morin, M. Leclerc, Macromolecules 2002, 35, 8413. e) A. P. Kulkarni, Y. Zhu, S. A. Jenekhe, Macromolecules 2005, 38, 1553.

[11] Z. Novák, P. Nemes, A. Kotschy, Org. Lett. 2004, 6, 4917.

[12] M. S. Yusybov, V. D. Filimonov, Synthesis 1991, 2, 131.

[13] M. Jandke, P. Strohriegl, S. Berleb, E. Werner, W. Brütting, Macromolecules 1998, 31, 6434.

[14] C. Janiak, J. Chem. Soc., Dalton Trans. 2000, 21, 3885 .

[15] H. W. Rothkopf, D. Wöhrle, R. Müller, G. Kossmehl, Chem. Ber $\mathbf{1 9 7 5}, 108,875$

[16] a) X. Zhan, Y. Liu, X. Wu, S. Wang, D. Zhu, Macromolecules 2002 35, 2529. b) T.-C. Chou, K.-C. Liao, J.-J. Lin, Org. Lett. 2005, 7, 4843.

[17] a) M. Thelakkat, H. Schmidt, Adv. Mater. 1998, 10, 219. b) C. Hohle, U. Hofmann, S. Schloter, M. Thelakkat, P. Strohriegl, D. Haarer, S. Zilker, J. Mater. Chem. 1999, 9, 2205. c) J. Pommerehne, H. Vestweber, W. Guss, R. F. Mahrt, H. Bässler, M. Porsch, J. Daub, Adv. Mater 1995, 7, 551

[18] a) C.-C. Wu, T.-L. Liu, W.-Y. Hung, Y.-T. Lin, K.-T. Wong, R.-T. Chen, Y.-M. Chen, Y.-Y. Chien, J. Am. Chem. Soc. 2003, 125, 3710. b) L.-Y. Chen, W.-Y. Hung, Y.-T. Lin, C.-C. Wu, T.-C. Chao, T.-H Hung, K.-T. Wong, Appl. Phys. Lett. 2005, 87, 112 103. c) P. M. Borsenberger, D. S. Weiss, Organic Photoreceptors for Imaging Systems, Marcel Dekker, New York 1993.

[19] a) H. Bässler, Int. J. Mol. Phys. 1994, 8, 847. b) H. Bässler, Philos. Mag. B. 1992, 65, 795. c) W. D. Gill, J. Appl. Phys. 1972, 43, 5033.

[20] Y. Li, M. K. Fung, Z. Xie, S.-T. Lee, L.-S. Hung, J. Shi, Adv. Mater 2002, 14,1317

[21] K. R. Justin Thomas, J. T. Lin, Y.-T. Tao, C.-H. Chuen, Chem. Mater. 2002, 14, 2796.

[22] N. Tamoto, C. Adachi, K. Nagai, Chem. Mater. 1997, 9, 1077.

$[23]$ a) J. J. Eisch, L. E. Hallenbeck, K. I. Han, J. Am. Chem. Soc. 1986, 108, 7763. b) H. M. Colquhoun, J. Holton, D. J. Thompson, M. V. Twigg, New Pathways for Organic Synthesis 1984, Ch. 9.

[24] I.-Y. Wu, J. T. Lin, Y.-T. Tao, E. Balasubramaniam, Y.-Z. Su, C.-W. Ko, Chem. Mater. 2001, 13, 2626. 